\title{
The effects of lexical and semantic information on same-different visual comparison of words
}

\author{
RODERICK W. BARRON \\ University of Guelph, Guelph, Ontario, Canada N1G 2W1 \\ and \\ LESLIE HENDERSON \\ The Hatfield Polytechric, Hatfield, Herts, England AL10 9AB
}

\begin{abstract}
Previous research has indicated that phonemic and orthographic factors cannot account for the fact that words (clear/clear) are responded to more rapidly than orthographically legal nonwords (creal/creal) in a same-different visual comparison task. However, the role of semantic and lexical factors is less certain. The effects of semantic similarity on both same and different judgments were evaluated in several experiments. In the first experiment, subjects were not any slower on semantically related (rang/rung) than on unrelated (rang/rank) different judgments even with a 3,000-msec interval between the first and second word. In Experiment 2, subjects based their judgments on whether or not the first letter of each word was visually identical. Same judgments were not any faster for semantically related than unrelated items even though other evidence indicated that subjects were processing the whole word and not just the first letter. Experiment 3 showed that the word/orthographically legal nonword difference could be replicated with the first-letter visual comparison task employed in Experiment 2. These and related results were discussed with reference to the idea that the word/orthographically legal nonword difference is due to the facilitating effects of a lexical entry upon the encoding, but not the comparison of an item.
\end{abstract}

In a same-different visual comparison task (e.g., Eichelman, 1970), subjects are required to respond "yes" or "same" if two words are visually identical (e.g., read/read); otherwise, they are required to respond "no" or "different" (e.g., word/read). Although there is nothing in the requirements of this task that necessitates access to the internal lexicon, several recent experiments can be interpreted as indicating that lexical access does, in fact, take place. The basic evidence (Barron \& Pittenger, 1974; Chambers \& Forster, 1975) is that same judgments for words (e.g., clear/clear) are made more rapidly than for orthographically legal nonwords (e.g., creal/creal). This result has also been obtained by Baron (1975), who showed that same judgments for words are $23 \mathrm{msec}$ faster than for legal nonwords. In addition, similar word/legal nonword differences have been obtained in visual search (Kreuger,

This research was supported by National Research Council Grant A9782 to Roderick W. Barron and by Social Science Research Council Grant 3301/1 to Leslie Henderson. We thank Lynne Dennis and David Woodhouse for testing the subjects in Experiments 1a and 1b, respectively, and Colleen MacFadden for testing the subjects in Experiments 3 and 4. We also thank Derek Besner, Alexander Pollatsek, and Harvey Marmurek for their comments on an earlier draft of this paper. Portions of these data were presented at the Canadian Psychological Association Meetings, Toronto, Canada, June 1976. Requests for reprints should be addressed to Roderick W. Barron, Department of Psychology, University of Guelph, Guelph, Ontario, Canada N1G 2W1.
1970) and in tachistoscopic probe-recognition tasks (Manelis, 1974; McClelland, 1976; Juola, Choe, \& Leavitt, Note 1) where, as with the visual comparison task, lexical access is not a logical requirement of task performance.

Besides lexical access, there are several other ways of accounting for the word/legal nonword difference obtained in the visual comparison task. It is possible that words may differ from the legal nonwords used in these studies in their conformity to the structure of English orthography as well as in their possession of a lexical entry. However, even if this were the case, it could not be used to account for Chambers and Forster's (1975) finding that same judgments for highfrequency words (e.g., bird/bird) are faster than for low-frequency words (e.g., beef/beef). Furthermore, it cannot be used to account for the results obtained by Henderson (1974) that same judgments for meaningful, but orthographically illegal nonwords (e.g., FBI/FBI) are faster than for items which are both nonmeaningful and orthographically illegal (e.g., IBF/IBF). In summary, the evidence for lexical access in visual comparison tasks cannot be explained solely by differences in orthographic structure.

It is possible, however, that the results obtained by Chambers and Forster (1975) and by Henderson (1974) can be interpreted as involving semantic rather than just lexical access. We use the term lexical to refer to the idea that a word has an address or location in the internal lexicon which may represent that word without 
necessarily embodying its semantic characteristics. Hence, READ and FBI would have entries in the lexicon, whereas REAT and IBF would not. We use the term semantic to refer to the idea that an item (e.g., READ or FBI) actually undergoes semantic processing in addition to obtaining access to an entry in the internal lexicon. According to our lexical-semantic distinction, semantic processing can be said to have taken place when information becomes available about a word's semantic properties such as its location in the semantic memory system (e.g., Collins \& Loftus, 1975; Meyer \& Schvaneveldt, 1971) or its semantic features (e.g., Smith, Shoben, \& Rips, 1974).

Neither the word/legal nonword difference nor the frequency effect obtained by Chambers and Forster (1975) allows us to distinguish lexical from semantic access interpretations of visual comparison data. Furthermore, the FBI-IBF difference obtained by Henderson (1974) can be interpreted as either a lexical or a semantic effect. What is needed, then, is a uniquely semantic manipulation in a visual comparison task whereby the semantic similarity of the words is varied. In our first experiment, we attempted to show that different judgments in a same-different visual comparison task are influenced by semantic similarity by comparing pairs of words which are related in meaning (e.g., rang/rung) to pairs of words which are unrelated in meaning (e.g., rang/rank). If semantic access is involved in visual comparison judgments, then the different judgments for the semantically related pairs should take longer than the semantically unrelated pairs because of the greater likelihood that the semantically related items are adjacent or share features in semantic memory.

The question of whether semantic similarity would also influence the same judgments in a visual comparison task was addressed in Experiment 2. Chambers and Forster (1975) have shown that different judgments for words and legal nonwords do not differ even when $80 \%$ of the letters are shared between the words making up each pair and the location of the nonidentical letter is in the middle and final serial positions. These results contrast sharply with the highly reliable word/legal nonword difference which has been obtained with same judgments. This and other differences in the variables which influence same and different judgments have prompted a number of investigators (e.g., Bamber, 1969; Barron \& Pittenger, 1974; Egeth \& Blecker, 1971; Henderson, 1974; Henderson \& Henderson, 1975; Krueger, 1973) to argue that same judgments are relatively fast and holistic, whereas different judgments are slower and more analytic.

In order to deal with the possibility that semantic similarity may have different effects upon same than upon different judgments, the subjects in our second experiment were required to respond "same" if the first letter of one word was identical to the first letter of the second word in a pair (e.g., rang/rung); otherwise, a "different" response was required (e.g., depth/teeth). If semantic access is involved in same judgments, and if it can be shown that subjects actually process the whole word when they are required to base their decisions upon the first letter of each word in a pair, then the semantically related pairs (e.g., rang/rung) should be faster than the semantically unrelated pairs (e.g.. rang/rank). In addition, using same judgments to assess the effects of semantic similarity on visual comparison avoids the problems of interpretation associated with the possibility that semantic similarity may facilitate encoding, but slow comparison processes for different judgments. Semantic similarity should facilitate both encoding and comparison processes for same judgments.

Experiments 3 and 4 were carried out in order to counter possible criticisms of the single-letter visual comparison task used in Experiment 2 and the strength of the semantic relatedness manipulation in Experiments 1 and 2. Specifically, Experiment 3 was designed to find out whether the word/legal nonword difference could be obtained when subjects were required to decide whether the first letter of one word was identical to the first letter of the other word in a pair. Experiment 4 was designed to find out how subjects would rate the word pairs used in Experiments 1 and 2 in semantic relatedness, and how these ratings correlated with performance.

\section{EXPERIMENT 1}

\section{Method}

Stimulus materials. Sixty pairs of words requiring a same judgment and 60 pairs of words requiring a different judgment were used. Thirty of the different judgment pairs were semantically related (SR) and the other 30 pairs were semantically unrelated (SU). In order to maximize the likelihood that subjects would base their different judgments on semantic rather than graphemic information, the $S R$ and $S U$ pairs were constructed so that the words making up each pair were identical in length (mean $=5.43$ letters) and shared a large number of letters in common. The average percentage of identical letters in corresponding letter positions (e.g., a $G$ in the third-letter position in both words) was $61 \%$ for both the $S R$ and SU conditions. In addition, the first letter of the first word was identical to the first letter of the second word for all pairs in both conditions. Finally, the SR and SU words were identical in length and the number of shared letters at each letter position was highly correlated $(r=+.96)$ between the two conditions. Based on the Kucera and Francis (1967) word-frequency norms, the SR and SU conditions were very similar in overall frequency (mean $=23.61$ and mean $=24.83$, respectively) and in the frequency difference between the two words making up each pair (mean $=24.27$ and mean $=24.10$, respectively). The $S R$ and SU word pairs are presented in Appendix A. The 60 words used for the same judgments averaged 5.40 letters in length and had an average frequency of 20.92 .

Procedure. The word pairs were presented in a different random order to each subject on a four-channel Iconix tachistoscope, with the constraint that neither a response nor a word type could appear more than four times in succession. In Experiment $1 \mathrm{a}$, both words appeared simultaneously one above the other (the top-bottom order of the words was reversed for half of the subjects) for $500 \mathrm{msec}$. The visual angle subtended by each word was $.28 \mathrm{deg}$ on the vertical axis and 
ranged between 1.09 and $2.03 \mathrm{deg}$ on the horizontal axis. The vertical axis visual angle for the complete display was $.96 \mathrm{deg}$. Experiment $1 \mathrm{~b}$ was identical to Experiment la except that the first word of each pair appeared for $500 \mathrm{msec}$ and was replaced by a patterned mask which lasted $3,000 \mathrm{msec}$. This mask was then replaced by the second word of the pair which also appeared for $500 \mathrm{msec}$. The two words were located one above the other with the top-bottom order being reversed for half of the subjects. The visual angle subtended by each word in Experiment $1 \mathrm{~b}$ was $.28 \mathrm{deg}$ in the vertical axis and ranged from 1.09 to $2.03 \mathrm{deg}$ in the horizontal axis. The words were printed in uppercase letters in both experiments. The subject's latency to respond was recorded in milliseconds from the onset of the display in Experiment 1a and from the onset of the second word in Experiment 1b. In both experiments, the timer was stopped by a vocal "yes" or "no" response via a Scientific Prototype audio threshold device. These responses represented the same and different decisions, respectively.

The subjects were instructed to fixate a small cross in the center of the viewing field and were told that they could press the button which they held in their hand when they were ready to see the display. The display appeared as soon as they pressed the button. They were instructed to respond "yes" if the two words were visually identical, and otherwise to respond "no." In addition, the subjects in Experiment $1 \mathrm{~b}$ were told that there would be a delay between the presentation of the first and second words. Both groups of subjects were cautioned against making errors. In order to familiarize the subjects with the procedure and apparatus, 20 practice trials were given using words which did not appear in the actual experiment.

Subjects. Thirty-two subjects participated in Experiment 1a and 30 subjects in Experiment $1 \mathrm{~b}$. All 62 subjects were students in undergraduate psychology courses at the University of Guelph.

\section{Results and Discussion}

Mean reaction times based on the correct latencies were obtained in each condition both for individual subjects (summed across word pairs) and individual word pairs (summed across subjects) in Experiments la and 1b. The means for individual subjects were used in an $\mathbf{F}_{1}$ analysis of variance and the means for individual word pairs were used in an $F_{2}$ analysis of variance. $A$ min $F^{\prime}$ was computed using these $F_{1}$ and $F_{2}$ values (Clark, 1973). Table 1 shows that same judgments were made more rapidly than different judgments in both Experiments 1a $\left[F_{1}(1,31)=10.00, p<.005\right]$ and $1 b$ $\left[F_{1}(1,29)=9.11, p<.01\right]$. An analysis of the different judgments (Table 1) shows that the semantically related pairs were not faster than the semantically unrelated pairs in Experiment 1a $\left[\min F^{\prime}(1,65)<1\right.$; $\left.F_{1}(1,31)=2.69, \quad p>.10 ; \quad F_{2}(1,62)<1\right] \quad$ or in Experiment $1 \mathrm{~b} \quad\left[\min \mathrm{F}^{\prime}(1,65)<1 ; \quad \mathrm{F}_{1}(1,29)=6.70\right.$, $\left.p<.05 ; F_{2}(1,58)<1\right]$. The only exception to this finding was the significant $F_{1}$ in Experiment $1 \mathrm{~b}$. Table 1 also shows that the error rates were low $(3.61 \%$ in Experiment $1 \mathrm{a}$ and $3.05 \%$ in Experiment $1 \mathrm{~b}$ ) and did not differ between the SR and SU conditions in either Experiment 1a $\left[F_{1}(1,31)<1\right]$ or $1 \mathrm{~b}\left[F_{1}(1,29)=1.48\right.$, $\mathrm{p}>.10]$.

The failure to obtain a semantic similarity effect with the different judgments in either Experiment 1a or $1 \mathrm{~b}$ indicates that semantic information is not used
Table 1

Mean Reaction Times (RT) and Percent Errors (\%E) for the "Same" Responses and for the Semantically Related (SR) and Unrelated (SU) "Different" Responses in Experiments 1a and $1 \mathrm{~b}(3,000-\mathrm{msec}$ Interword Delay)

\begin{tabular}{cccc}
\hline & \multicolumn{3}{c}{ Response Type } \\
\cline { 2 - 4 } & Same & SR Different & SU Different \\
\hline RT & 899 & Experiment 1a \\
$\% \mathrm{E}$ & 2.92 & 921 & 932 \\
& \multicolumn{4}{c}{ Experiment $1 \mathrm{~b}$} \\
RT & 635 & 660 & 649 \\
$\% \mathrm{E}$ & 4.17 & 2.11 & 2.88 \\
\hline
\end{tabular}

in making different visual comparisons. These results were obtained even though there was considerable letter overlap between the word pairs which should minimize the use of purely graphemic information in deciding that two words are different. Furthermore, semantic information does not appear to be used even when there could be a memory advantage to representing the first word in a semantic code over the 3,000-msec interword interval in Experiment $1 \mathrm{~b}$.

Finally, our failure to find a semantic similarity effect with the different judgments does not conflict with the findings of Schaeffer and Wallace (1970), who did obtain a semantic similarity effect. The subjects in Schaeffer and Wallace's experiment were required to make a judgment about whether two words belonged to the same semantic category, whereas our subjects were only required to decide whether two words were visually identical.

\section{EXPERIMENT 2}

Despite the fact that we did not obtain semantic similarity effects for the different judgments in Experiments $1 \mathrm{a}$ and $1 \mathrm{~b}$, it is possible that such effects might be obtained with same judgments because same judgments are supposed to be holistic and because word/legal nonword differences have been obtained with them most often. Experiment 2 was addressed to this problem. Since pairs of words which are semantically similar (e.g., rang/rung) cannot also be visually identical, it was necessary to alter the visual comparison task in order to accommodate this problem. Our solution was to require the subjects to respond "yes" if the first letter of the first word was visually identical to the first letter of the second word (e.g., advise/advice) in a pair of words; otherwise, the response was "no" (e.g., cedar/radar). We predicted that if semantic access is involved in same judgments, then the semantically related pairs should be faster than the semantically unrelated pairs.

There was another reason for carrying out Experiment 2. It is possible that our failure to find a difference between the semantically related and 
unrelated words in Experiments $1 \mathrm{a}$ and $1 \mathrm{~b}$ might be due to semantic similarity slowing word comparison, but facilitating word encoding for different judgments (e.g., the word which is encoded first might serve as a priming stimulus for the second word). These two effects might cancel out each other, thus producing the results we obtained. ${ }^{1}$ Experiment 2, however, avoids this problem because semantic similarity should facilitate both encoding and comparison processes for same judgments.

In order to find out if the subjects were processing the whole word and not just the first letter (on which they based their decisions), we included same word pairs which were both visually, and therefore, semantically identical (e.g., part/part). If subjects were processing the whole word in making same judgments, then these identical pairs should be faster than the pairs which were just semantically similar. Conversely, if only the first letter was being processed, then there should be no differences among the three same judgment conditions. As a further check on whether the subjects were processing the whole word or just the first letter, half of the different judgment pairs were constructed so that they shared a high percentage of their letters in corresponding letter positions (e.g., depth/teeth) and the other half were constructed so that they shared a low percentage of their letters in corresponding letter positions (e.g., chant/fence). Since several investigators (e.g., Chambers \& Forster, 1975) have shown that reaction time is positively correlated with letter overlap, we predicted that the high letter-overlap pairs should be slower than the low letter-overlap pairs if subjects were processing more of the word than the first letter.

\section{Method}

Stimulus materials. All of the word pairs used for the different judgments in Experiments $1 \mathrm{a}$ and $1 \mathrm{~b}$ were used for the same judgments in Experiment 2. In addition, 10 word pairs were added to each condition for a total of 40 semantically related (SR) and 40 semantically unrelated (SU) same judgment pairs. As in Experiments $1 \mathrm{a}$ and $1 \mathrm{~b}$, the length of the words making up each word pair was identical. The average length of the words in the SR and SU conditions was 5.44 letters. The SR word pairs shared $63 \%$ of their letters in corresponding letter positions and the SU word pairs, 60\%. The correlation between the SR and SU pairs in the number of shared letters in each letter position was $r=+.98$. The overall frequency (Kučera \& Francis, 1967) of the SR words was 28.33 and that of the SU words was 31.10. The average frequency difference between the two words making up each pair was 29.38 for the SR word pairs and 31.28 for the SU word pairs. There were 40 visually identical same pairs, hereafter referred to as the identical (I) pairs. The average length of these word pairs was 5.33 letters and their average frequency was 30.70 . Finally, the average frequency of the first letter Mayzner \& Tresselt, 1965) of the words in the I (225), SR (185), and SU (187) conditions did not differ $[F(2,111)<1]$, hence any differences in reaction time among the three conditions cannot be attributed to differences in the frequency of the letters on which subjects based their decisions.

Eighty different judgment pairs were also used. Forty of these different pairs shared approximately the same percentage of letters $(60.15 \%)$ as the SR and SU pairs (e.g., rush/push), although not in the same positions as the SR and SU pairs (i.e., there were no shared letters in the first-letter position) Hereafter, we will refer to these letter pairs as the high sharedletter different pairs (HSL). Both members of the pair were identical in number of letters and their average length was 5.28 letters. Their overall frequency was 30.15 , and the average frequency difference between the two words making up each pair was 34.38 . The other 40 different pairs were comparable to the HSL pairs in overall length (5.05 letters), overall frequency (29.95), and frequency difference (30.65). They differed from the HSL pairs because a very small percentage of the letters were shared between the two words making up each pair $(3.68 \%)$. Hereafter, these word pairs will be referred to as low shared-letter (LSL) different pairs. Finally, the average first-letter frequency for both the HSL and LSL words was 232. The words used in Experiment 2 are presented in Appendix B.

Procedure. All 200 word pairs were presented in a different random order to each subject on an Electronics Developments two-channel tachistoscope with the constraint that neither a response nor a word type could appear more than four times in succession. The words were printed in lowercase type, appeared one above the other, and were presented simultaneously. The visual angle of each word in the vertical axis was $.15 \mathrm{deg}$ and the visual angle of the words in the horizontal axis ranged from .4 to $1.2 \mathrm{deg}$. The visual angle for the vertical axis of the display (i.e., two words) was $.7 \mathrm{deg}$. The subjects were instructed to respond "yes" by pushing a button with their dominant hand if the first letter of the first word was identical to the first letter of the second word in a pair of words Otherwise, they were instructed to respond "no" by pressing a second button with their nondominant hand. Hand dominance was established by asking the subjects which hand they wrote with. As in Experiments $1 \mathrm{a}$ and $1 \mathrm{~b}$, presentation of the stimuli was self-paced. The word display appeared as soon as the subject pressed a button located between the two response buttons. Ten practice trials made up of words not appearing in the experiment were given to each subject in order to insure acquaintance with the procedure and apparatus. Latency to respond was recorded from the onset of the display until the subject pressed a response button. The subjects were cautioned against making errors.

Subjects. Twenty-four undergraduate students at Hatfield Polytechnic served as subjects in the experiment. They were paid 50 pence for their participation.

\section{Results and Discussion}

As in Experiments $1 \mathrm{a}$ and $1 \mathrm{~b}$, mean reaction times based on the correct latencies were obtained in each condition for individual subjects and word pairs. These means were used in separate analyses of variance for the same and different judgments. The two types of judgments were not directly compared because the same judgments were more frequent and all subjects used their dominant hand to respond "same."

A one-way analysis of variance on the same judgments indicated a significant main effect for condition $\left[\min F^{\prime}(2,112)=15.70, p<.001 ; \quad F_{1}(2,46)=26.81\right.$, $\left.\mathrm{p}<.001 ; \mathrm{F}_{2}(2,117)=37.86, \mathrm{p}<.001\right]$. Table 2 shows that the I same pairs were faster than either the SR or SU same pairs. This was confirmed by an orthogonal comparison of the I pairs with the SR and SU pairs $\left[\min F^{\prime}(1,123)=28.83, \quad p<.001 ; \quad F_{1}(1,46)=53.36\right.$, $\left.\mathrm{p}<.001 ; \quad \mathrm{F}_{2}(1,117)=62.73, \quad \mathrm{p}<.001\right] . \quad$ More importantly, Table 2 also shows that there was 
Table 2

Mean Reaction Time (RT) and Percent Errors (\%E) for the Semantically and Visually Identical (I), Semantically Related (SR), and Semantically Unrelated (SU) "Same" Responses, and for High Shared-Letter (HSL) and Low Shared-Letter (LSL) "Different" Responses in Experiment 2

\begin{tabular}{|c|c|c|c|c|c|}
\hline & \multicolumn{5}{|c|}{ Response Type } \\
\hline & \multicolumn{3}{|c|}{ Same } & \multicolumn{2}{|c|}{ Different } \\
\hline & I & SR & SU & HSL & LSL \\
\hline $\begin{array}{l}\text { RT } \\
\% E\end{array}$ & $\begin{array}{l}516 \quad .94 \\
\quad\end{array}$ & $\begin{array}{l}552 \\
2.92\end{array}$ & $\begin{array}{l}555 \\
3.44\end{array}$ & $\begin{array}{l}615 \\
4.48\end{array}$ & $\begin{array}{l}592 \\
2.81\end{array}$ \\
\hline
\end{tabular}

no significant difference between the $\mathrm{SR}$ and $\mathrm{SU}$ same judgments $\left[\min F^{\prime}(1,119)<1 ; \quad F_{1}(1,46)<1 ;\right.$ $\left.F_{2}(1,117)<1\right]$. The different judgment data are also presented in Table 2 . They indicate that the HSL (high shared letter) condition was slower than the LSL (low shared letter) condition $\left[\mathrm{min} \mathrm{F}^{\prime}(1,100)=8.38\right.$, $\mathrm{p}<.005 ; \mathrm{F}_{1}(1,23)=43.06, \mathrm{p}<.001 ; \mathrm{F}_{2}(1,78)=10.41$, $p<.01]$. The overall error rate was low $(2.92 \%)$ and neither the $S R$ and $S U$ same judgments $\left[F_{1}(1,23)=2.39\right.$, $\mathrm{p}>.10]$ nor the HSL and LSL different judgments $\left[F_{1}(1,23)=3.17, p>.05\right]$ were significantly different from each other in error percentage.

The failure to obtain a significant difference between the semantically related and unrelated words for the same judgments parallels the results we obtained for the different judgments in Experiments $1 \mathrm{a}$ and $1 \mathrm{~b}$. As was the case with the different judgments, the same judgments do not appear to have involved the use of semantic information. Furthermore, the absence of a difference between the SR and SU words cannot be attributed to differential effects of semantic similarity on encoding and comparison. The fact that the I same judgments were faster than the SR and SU same judgments indicates that subjects were processing the whole word and not just the single letter on which they were instructed to base their decisions. Accordingly, these data suggest that our failure to find a difference between the SR and SU pairs cannot be attributed to a lack of sensitivity of our task. Finally, our finding that different word pairs with a high percentage of shared letters (HSL) were slower than those with a low percentage of shared letters (LSL) is similar to the results obtained by Barron and Pittenger (1974) and Chambers and Forster (1975), who found that degree of letter overlap correlated positively with reaction time for different judgments.

\section{EXPERIMENT 3}

One possible criticism of the results of Experiment 2 is that we do not know if the word/legal nonword difference can be replicated with the first-letter visual comparison task we used. If it cannot be replicated with our task, then the results of Experiment 2 (i.e., no difference between semantically related and unrelated word pairs) could be interpreted as a taskspecific phenomenon which offers no evidence one way or the other about whether semantic information is involved in the word/legal nonword difference in visual comparison. In order to respond to this possible criticism, we attempted to replicate the word/legal nonword difference with our first-letter visual comparison task by using the words and legal nonwords employed by Chambers and Forster (1975) in their second experiment.

\section{Method}

Stimulus materials. Forty pairs of words and 40 pairs of orthographically legal nonwords were used for the same judgments; similarly, 40 word and 40 orthographically legal nonword pairs were used for the different judgments, for a total of 160 pairs of items. All of the words were five letters in length. The pairs of items used for our same judgments were taken directly from the Appendix for Chambers and Forster's (1975) second experiment. Although the items making up our different pairs were also taken from the Appendix for their second experiment, they were rearranged so that the items making up a pair did not have identical first letters. The average percentage of identical letters in corresponding letter positions (two through five) between the items in a pair was $4.06 \%$ for the words and $8.13 \%$ for the legal nonwords. The word and legal nonword pairs used in Experiment 3 are presented in Appendix C.

Chambers and Forster (1975) constructed their legal nonwords so that they had higher mean bigram (Mayzner \& Tresselt, 1965) and trigram (Mayzner, Tresselt, \& Wolin, 1965) frequency counts than their words (i.e., 325 vs. 240 and 79 vs. 44 for bigrams and trigrams, respectively). These bigram and trigram frequency counts have been interpreted as gross measures of orthographic regularity (e.g., Gibson, Shurcliff, \& Yonas, 1970) because the frequency of an individual letter cluster was computed separately for each position it could occupy within a word. Finally, the frequency of the first letter (Mayzner \& Tresselt, 1965) was 255 for words and 260 for nonwords for same judgments $[F(1,78)<1]$, and 237 for words and 278 for nonwords for the different judgments $[F(1,158)=3.83, p>.05]$.

Procedure. The word pairs were typed one above the other in lowercase type onto $2.5 \mathrm{~cm} \mathrm{x} 4.0 \mathrm{~cm}$ white labels. These labels were pasted onto white stimulus transport paper and outlined in black for presentation in a single channel of a Scientific Prototype three-channel tachistoscope. The visual angle of a pair of items was $.32 \mathrm{deg}$ in the vertical and $.53 \mathrm{deg}$ in the horizontal dimension. The subjects were instructed to respond "yes" or "same" by pressing one telegraph key with their dominant hand if the first letter of one item was identical to the first letter of the other item in a pair. If the letters were not identical, then they were instructed to respond "no" or "different" by pressing a second telegraph key with their nondominant hand. Hand dominance was established by asking the subjects which hand they wrote with. A trial was initiated when the experimenter said "ready" and pressed a button which started the tachistoscope. Five hundred milliseconds after the experimenter pressed the button, a word pair was displayed for 500 msec. The subject's reaction time was recorded from the onset of the display until either the same or different telegraph key was pressed. The subjects were instructed to respond as fast as they could, but they were cautioned against making errors.

The 160 same and different word and legal nonword pairs were divided into four lists of 40 pairs made up of 10 same 
word, 10 same nonword, 10 different word, and 10 different nonword pairs. Each list of $\mathbf{4 0}$ pairs was randomized with the constraint that an item pair or a response type could not appear more than four times in succession. The order of the four lists was varied across subjects so that each list was presented first, second, third, or fourth equally often. The subjects were given 20 practice items which did not appear in the experiment proper in order to acquaint them with the apparatus and procedure.

Subjects. Thirty-two subjects participated in the experiment. They were all students in undergraduate psychology courses at the University of Guelph.

\section{Results and Discussion}

As in the previous experiment, mean correct reaction times were obtained in each condition for both individual subjects and item pairs. Overall, same judgments were faster than different judgments $[F(31)=9.99, p<.005]$. Table 3 shows that the same judgments were $42 \mathrm{msec}$ faster for the words than for the orthographically legal nonwords $\left[\min \mathrm{F}^{\prime}(1,104)=5.46, \quad \mathrm{p}<.025 ; \quad \mathrm{F}_{1}(1,31)=28.84\right.$, $\left.\mathrm{p}<.001 ; \mathrm{F}_{2}(1,78)=6.74, \mathrm{p}<.025\right]$. The error rate for the same judgments was very low $(.82 \%)$ and the words did not differ from the nonwords $[F(1,31)<1]$. The different judgments, however, were not significantly faster for the words than for the legal nonwords $\left[\min F^{\prime}(1,96)=1.30, \quad p>.10 ; \quad F_{1}(1,31)=11.16\right.$, $\left.\mathrm{p}<.005 ; \mathrm{F}_{2}(1,78)=1.47, \mathrm{p}>.10\right]$. The only exception to this finding was the significant $F_{1}$ analysis. The error percentage for the different judgments was also very low $(.82 \%)$, and Table 3 shows that the subjects made more errors on the words than on the legal nonwords $[F(1,31)=6.82, p<.025]$. These error data suggest the possibility that subjects may have reduced their accuracy in order to increase their speed on the words relative to the nonwords. Mean reaction times for the individual word pairs are presented in Appendix $C$.

The results of this experiment indicate that we were able to replicate the word/legal nonword difference for same judgments (Chambers \& Forster, 1975) with our first-letter visual comparison task. Furthermore, we were able to replicate Chambers and Forster's (1975) finding that different judgments for words are not faster than those for legal nonwords. These results provide additional support for the idea that the absence of a semantic similarity effect for same judgments in

Table 3

Mean Reaction Time (RT) and Percent Errors (\%E) for "Same" and "Different" Responses to Words and to Orthographically Legal Nonwords in Experiment 3

\begin{tabular}{|c|c|c|c|}
\hline \multirow[b]{2}{*}{ Type of Item } & & \multicolumn{2}{|c|}{ Response Type } \\
\hline & & Same & Different. \\
\hline Words & $\begin{array}{l}\mathrm{RT} \\
\% \mathrm{E}\end{array}$ & $\begin{array}{r}838.70 \\
.70\end{array}$ & $\begin{array}{r}877 \\
1.25\end{array}$ \\
\hline Legal Nonwords & $\begin{array}{l}\mathrm{RT} \\
\% \mathrm{E}\end{array}$ & $\begin{array}{r}880 \\
\quad .94 \\
\end{array}$ & $\begin{array}{r}896 \\
.39\end{array}$ \\
\hline
\end{tabular}

Experiment 2 was not simply due to the characteristics of the first-letter visual comparison task, because we have shown that a word/legal nonword difference for same judgments can be obtained with that task. The results of Experiment 3 are also consistent with the idea that subjects were processing the whole word and not just the individual letter identities of the words in the same judgment condition in Experiment 2 . If subjects were only processing individual letter identities in a first-letter visual comparison task, then it is unlikely that we would have obtained our word/legal nonword difference.

\section{EXPERIMENT 4}

Another possible criticism of the results of Experiment 2 , as well as those of Experiments $1 \mathrm{a}$ and $1 \mathrm{~b}$, is that our manipulation of the semantic similarity. variable was weak. Our word pairs were matched on frequency, number of letters, and degree of letter overlap (which was over 60\%); consequently, it was difficult to satisfy-also the criteria that one half of the pairs be semantically related and the other half be semantically unrelated. Although at least half of the semantically related word pairs had the same morphological root, we needed to obtain a more objective measure of the semantic relatedness of our word pairs. Therefore, we required subjects to rate each word pair on the extent to which its members were related in meaning. These ratings were then correlated with the subjects' performance in Experiments 1a, $1 \mathrm{~b}$, and 2 .

\section{Method}

Materials. The word pairs we designated as being semantically related and unrelated in Experiment 2 were typed onto a sheet of paper in random order. These 80 word pairs included all of the word pairs designated as semantically related and unrelated in Experiments $1 \mathrm{a}$ and $1 \mathrm{~b}$ and they were preceded and followed by five buffer word pairs which were not used in any of the other experiments.

Procedure. The subjects were instructed to rate each pair of words on a 5-point scale on the extent to which its members were related in meaning. The subjects were told that a rating of 5 meant highly related in meaning, 4 meant related in meaning, 3 meant moderately related in meaning, 2 meant slightly related in meaning, and 1 meant unrelated in meaning. The subjects were instructed to mark their rating on a line next to each word pair and to take as long as they needed to complete the list.

Subjects. Thirty-two subjects rated the word pairs in Experiment 4 immediately after participating in Experiment 3, but before they were debriefed about its purpose. None of the subjects had participated in Experiments 1a, 1b, or 2 .

\section{Results and Discussion}

The average rating for the semantically related word pairs was 3.53 and the average rating for the semantically unrelated word pairs was 1.07 . Every subject gave the semantically related words a higher rating than the semantically unrelated words. The 
average rating for each of the individual word pairs was also determined and the range of the values obtained for the semantically related and unrelated pairs overiapped by only $2.5 \%$. The difference between the semantically related and unrelated pairs was highly significant $\left[\min \mathrm{F}^{\prime}(1,93)=153.32, \mathrm{p}<.001\right.$; $F_{1}(1,31)=1,543.70, \quad p<.001 ; \quad F_{2}(1,78)=170.23$, $\mathrm{p}<.001]$.

In order to find out if the semantic similarity ratings were related to performance in our experiments, we correlated the mean ratings for the individual word pairs with the mean reaction time for those word pairs in Experiments $1 \mathrm{a}, 1 \mathrm{~b}$, and 2. The mean ratings for the individual words are reported in Appendix A (Experiments 1a and 1b) and Appendix B (Experiment 2). All of the correlations were low and nonsignificant. [The correlation was $\mathrm{r}=-.10, \mathrm{t}(58)<1$ in Experiment 1a; $\mathrm{r}=+.02, \mathrm{t}(58)<1$ in Experiment 1b; and $\mathrm{r}=-.05, \mathrm{t}(78)<1$ in Experiment 2.] In addition, we recomputed the correlations for those word pairs with mean ratings which were no less than 4.00 and no greater than 1.00. Thirty word pairs met these criteria in Experiments $1 \mathrm{a}$ and $1 \mathrm{~b}$, and 40 word pairs met these criteria in Experiment 2. All of the word pairs with mean rating scores no less than 4.00 were semantically related and all of the word pairs with mean ratings no greater than 1.00 were semantically unrelated. Again, the correlations were low and nonsignificant. [The correlation was $r=-.13, t(1,28)<1$ for Experiment $1 \mathrm{a} ; \mathrm{r}=+.10, \mathrm{t}(28)<1$ for Experiment $1 \mathrm{~b}$; and $r=-.05, t(38)<1$ for Experiment 2.]

The results of this rating study indicate that the word pairs which we designated as being semantically related in Experiments $1 \mathrm{a}, 1 \mathrm{~b}$, and 2 obtained ratings of relatedness in meaning which were substantially higher than those obtained for the word pairs which we designated as being semantically unrelated. Furthermore, we found that degree of semantic relatedness was not correlated with performance even when extreme rating scores were used. We think, therefore, that the evidence indicates that the absence of a difference in reaction time between the semantically related and unrelated word pairs in Experiments $1 \mathrm{a}, 1 \mathrm{~b}$, and 2 is not due to a weakness in our semantic similarity manipulation.

\section{GENERAL DISCUSSION}

The major purpose of the experiments we have reported was to find out if the word/legal nonword difference in the same-different visual comparison task can be attributed to the use of semantic information. We have been unable to obtain any evidence that semantic information is used in either same or different visual comparison judgments. Experiments $1 \mathrm{a}$ and $1 \mathrm{~b}$ both showed that the different judgments were not influenced by semantic similarity even though the SR and SU pairs shared a large percentage of their letters in corresponding letter positions and there was a 3,000-msec delay between the two words making up each pair (Experiment $1 \mathrm{~b}$ ). Experiment 2 showed that the same judgments were not influenced by semantic similarity when subjects based their judgments on whether or not the first letter of one word was identical to the first letter of a second word, even when other evidence indicated that they were processing the whole letter string. Finally, Experiment 3 showed that the word/legal nonword difference can be obtained with the first-letter visual comparison task we used in Experiment 2, and Experiment 4 showed that our manipulation of semantic similarity in Experiments 1a, $1 \mathrm{~b}$, and 2 was not weak.

The absence of any evidence that semantic information is used in same-different visual comparison is consistent with the results of a recent experiment by Rosch (1975, Experiment 5). She found that category names (e.g., furniture) did not prime visually identical (good) category members (e.g., chair/chair) under instructions to respond "same" only on the basis of visual identity. According to Rosch (1975), the category-name prime did not facilitate visual matching because there was not a common (i.e., semantic) mode of processing between the prime and the visually identical category instances. Rosch's (1975) results provide further support for our conclusion that semantic information is not used in same-different visual comparison.

Given that semantic access cannot be used to account for the word/legal nonword difference obtained in a same-different visual comparison task, we would like to consider several alternative explanations of that result. The first possibility is that words are faster than legal nonwords because words are easier to code phonemically. However, Baron (1975) and Pollatsek, Well, and Schindler (1975) have shown that phonemic codes are not used in simultaneous visual comparison. They found that different judgments for homophone pairs (e.g., four/fore) were not any slower than nonhomophone pairs which shared the same number of letters (e.g., sore/sour) in corresponding letter positions. Henderson and Chard (1976) have obtained similar results with same judgments. They found that the superiority of meaningful (e.g., FBI/FBI) over nonmeaningful initials (e.g., IBF/IBF) disappeared when the initials were presented in lowercase type (e.g., fbi), thus indicating that the effect of meaningfulness cannot be attributed to subjects' being able to retrieve more rapidly the phonemic code for meaningful initials. These results indicate that the word/legal nonword effect in simultaneous visual comparison cannot be attributed to the greater ease of coding words phonemically.

Orthography is a second possible basis for the word/legal nonword difference. As mentioned earlier, it is possible that words conform more closely to the structure of English orthography than legal nonwords and, for that reason, are responded to more rapidly. 
The word/legal nonword difference cannot be attributed to differences in orthographic regularity, at least as measured by bigram or trigram positional frequency (e.g., Mayzner \& Tresselt, 1965; Mayzner, Tresselt, \& Wolin, 1965), because this frequency factor was equated for among the high- and low-frequency words and the legal nonwords in Chambers and Forster's (1975) experiment, and because the nonwords had higher bigram and trigram frequencies than the words in our third experiment and in Chambers and Forster's second experiment. It is possible, however, that the words used by Chambers and Forster (1975) differed in single-letter positional frequency (Mayzner \& Tresselt, 1965). Mason (1975) has recently proposed that singleletter, rathe than bigram and trigram, positional frequency may more accurately measure the spatial redundancy in English orthography which, she argues, is used to facilitate word perception.

In order to find out if the word/legal nonword difference can be attributed to differences in spatial redundancy, we computed the summed single-letter positional frequency value for each word and legal nonword used in Chambers and Forster's (1975) experiments. We found that the correlations between the mean same judgment reaction times for individual words and legal nonwords and their respective summed single-letter positional frequencies were low and not significant for Chambers and Forster's (1975) first $[\mathrm{r}=-.12, \mathrm{t}(58)<1]$ and second $[\mathrm{r}=-.12, \mathrm{t}(78)=1.07$, $\mathrm{p}>.10]$ experiments, and for our third experiment $[\mathrm{r}=+.02, \mathrm{t}(78)<1]$. In order to avoid the possibility that Mayzner and Tresselt's (1965) frequency counts might be unreliable because they were based on a relatively small corpus of words $(20,000)$, we repeated the above analyses of Chambers and Forster's words with the single-letter positional frequency counts recently reported by Solso and King (1976). These frequency counts are based upon the Kučera and Francis (1967) word list of one million words. Again we obtained correlations which were low and nonsignificant between the mean same judgment reaction times for individual words and nonwords and their respective summed spatial frequencies in Chambers and Forster's (1975) first $[\mathrm{r}=-.11, \mathrm{t}(58)<1]$ and second $[\mathrm{r}=-.13$, $t(78)=1.16, p>.10]$ experiments and our third experiment $[\mathrm{r}=-.02, \mathrm{t}(78)<1]$. These results indicate that the word/legal nonword difference in visual comparison cannot be attributed to differences in orthographic structure as measured by single-letter positional frequency or by bigram or trigram positional frequency.

The idea that lexical access is involved in samedifferent visual comparison was proposed earlier as an altemative to the semantic hypothesis. Since the semantic as well as the phonemic and orthographic hypotheses appear questionable, we would like to elaborate upon the lexical hypothesis and show how it can be used to account for the results of our experiments as well as those of others. There are two issues which we need to address. The first is concerned with why having a lexical entry facilitates sarne visual comparison of high-frequency over low-frequency words, and words over orthographically legal nonwords. The second issue is concerned with why the above frequency and word/legal nonword differences are not generally obtained with different judgments.

We assume that a lexical entry can influence either the encoding or the comparison of an item. A lexical entry might facilitate the encoding of an item by constraining the feature and letter information which is used in forming a representation of the word. Unlike the information specifying a representation of a nonword, this information would have to be consistent with the fact that the item has an entry in the internal lexicon as well as with the orthographic structure of English. There are at least iwo possible conceptions of how a lexical entry could facilitate encoding (Henderson, in press). The first is based on the idea that there may exist features which represent units larger than single graphemes: transgraphemic features. Accordingly, words might be responded to more rapidly than legal nonwords because fewer transgraphemic features are necessary to form a representation of a word than a legal nonword. McClelland (1976), however, has obtained evidence which is not consistent with the notion of transgraphemic features. He found that the word/legal nonword difference is obtained in tachistoscopic recognition even when transgraphemic features are broken up by presenting the letters making up the items in alternating case (e.g., rEaD vs. rEaT).

The second view of lexical facilitation of encoding involves the assumption of a continuous interaction between the processes of visual feature extraction and stored information about an itern's graphemic, orthographic, and lexical characteristics. If these sets of stored information could be interrogated independently and simultaneously, then words would be faster than legal nonwords because visual feature information would have to be consistent with the constraints specified by an item's lexical characteristics as well as by its orthographic and graphemic characteristics.

A lexical entry could also facilitate the comparison process by allowing items with lexical entries to be compared as whole units, whereas legal nonwords might require multiple comparisons at the level of individual letters or letter clusters. Although the word/legal nonword difference would appear to be accounted for by lexical facilitation of either encoding or comparison, we tend to favor an encoding interpretation because it is difficult to understand, as Chambers and Forster (1975) point out, why high-frequency words would be compared more rapidly than lowfrequency words. It is more likely that high-frequency 
words place additional constraints upon the information which can specify a word's representation, or that highfrequency words can be searched for more rapidly.

The fact that lexical effects have not been obtained for different judgments (i.e., Barron \& Pittenger, 1974; Chambers \& Forster, 1975) may be part of the more general phenomenon that variables which influence the speed of same judgments may not also influence the speed of different judgments. Nevertheless, we offer an account of the absence of a word/legal nonword difference on different judgments which may not generalize to other stimulus domains. We propose that subjects may alter the way in which they encode two items if differences between those items are detected during comparison. We think that the subject begins the comparison process before he completely forms a representation of a word; in fact, encoding and comparison may begin at the same time. If a difference is detected between two words on the basis of visual feature, graphemic, orthographic, or lexical information, then a slower letter-by-letter or letter-cluster-by-lettercluster encoding process is used. Consequently, words which do not differ by many letters will be more likely to show a word/legal nonword difference (or at least a word/orthographically illegal nonword difference; e.g., Chambers \& Forster, 1975) because the encoding process, which we assume is more rapid for words, is more likely to be completed before differences are detected. Conversely, words which differ by many letters may be responded to very quickly (e.g., Chambers $\&$ Forster, 1975) because the encoding process may have only just started before there is sufficient evidence from the comparison process to respond "different." Finally, given the arguments presented above, the high degree of letter overlap $(60 \%)$ of the words used to make up the word pairs in Experiments 1a, $1 \mathrm{~b}$, and 2 would appear to offer an opportunity for demonstrating semantic similarity effects in visual comparison because encoding and comparison processes should be fairly well advanced before featural, graphemic, orthographic, or lexical mismatches are detected and further processing is forced to proceed at the level of letters or letter clusters.

In conclusion, we have presented evidence which indicates that the word/legal nonword difference in visual comparison cannot be attributed to semantic, phonemic, or orthographic factors. We argued that lexical factors can account for this difference in word perception by influencing the rate at which information is encoded. In addition, we argued that the reason the word/legal nonword difference is not obtained with different judgments is that subjects use a slower encoding process based on letters or letter clusters if they detect any differences between two words. Hence, the advantage of a lexical entry for encoding could be lost unless the words are visually similar.

\section{REFERENCE NOTE}

1. Juola, J. F., Choe, C. S., \& Leavitt. D. D. A reanalysis of the word superiority effect. Paper presented at the meeting of the Psychonomic Society. Boston, Mass. November 1974.

\section{REFERENCES}

BAMBer, D. Reaction times and error rates for samedifferent judgment of multidimensional stimuli. Perception \& Psychophysics. 1969, 6. 169-174.

BARon, J. Successive stages in word recognition. In P. M. A. Rabbit \& S. Dornic (Eds.), Attention and performance $V$. New York: Academic Press, 1975.

Barron, R. W., \& Pittenger, J. B. The effect of orthographic structure and lexical meaning on samedifferent judgments. Quarterly Journal of Experimental Psychology, 1974, 26, 566-581.

BESNER, D., \& JACKSON, A. Same-different judgments with words and nonwords: A word superiority/inferiority effect. Bulletin of the Psychonomic Society. 1975, 6, 578-580.

Chambers, S. M., \& Forster, K. I. Evidence for lexical access in a simultaneous matching task. Memory \& Cognition, 1975, 3, 549-559.

Clark, H. H. The language-as-fixed-effect fallacy: A critique of language statistics in psychological research. Journal of Verbal Learning and Verbal Behavior, 1973, 12, 335-359.

Collins, A. M., \& Loftus, E. F. A spreading activation theory of semantic processing. Psychological Review, $1975,82,407-428$.

EGETH, H., \& Blecker, D. Differential effects of familiarity on judgments of sameness and difference. Perception \& Psychophysics, 1971, 9, 321-326.

EichelmaN, W. H. Familiarity effects in a simultaneous matching task. Journal of Experimental Psychology. 1970. 86, $275-282$.

Gibson, E. J., Shurcliff, A., \& Yonas, A. Utilization of spelling patterns by deaf and hearing subjects. In $H$. Levin \& J. P. Williams (Eds.). Basic studies in reading. New York: Basic Books, 1970.

Henderson, L. A word superiority effect without orthographic assistance. Quarterly Journal of Experimental Psychology, 1974, 26, 301-311.

Henderson, L. Word recognition. In N. S. Sutherland (Ed.), Tutorial essays in experimental psychology. Hillsdale, N.J: Lawrence Erlbaum, in press.

Henderson, L., \& Chard, J. On the nature of the facilitation of visual comparisons by lexical membership. Bulletin of the Psychonomic Society. 1976, 7, 432-434.

Henderson, L., \& Henderson, S. E. Visual comparison of words and random letter strings: Effects of number and position of letters different. Memory \& Cognition, 1975, 3, 97-101.

KRUEGER, L. E. Search time in a redundant visual display. Journal of Experimental Psychology, 1970, 83, 391-399.

Krueger, L. E. Effect of irrelevant surrounding material on speed of same-different judgment of two adjacent letters. Journal of Experimental Psychology, 1973, 98, 252-259.

KUČERA, H., \& Francis, W. N. Computational analysis of present-day American English. Providence, R.I: Brown University Press, 1967.

Manelis, L. The effect of meaningfulness on tachistoscopic word perception. Perception \& Psychophysics, 1974, 16, 182-192.

Mason, M. Reading ability and letter search time: Effects of orthographic structure defined by single letter positional 
frequency. Joumal of Experimental Psychology: General, $1975,104,146-166$

Mayzner, M. S., \& Tresselt, M. E. Tables of single-letter and digram frequency counts for various word length and letter position combinations. Psychonomic Science Monograph Supplements, 1965, 1, 13-32.

Mayzner, M. S., Tresselt, M. E., \& Wolin, B. R. Tables of trigram frequency counts for various word length and position combinations. Psychonomic Science Monograph Supplements, 1965, 1, 33-78.

MeYeR, D. E., \& SChyane Veldt, R. W. Facilitation in recognizing pairs of words: Evidence of a dependence between retrieval operations. Journal of Experimental Psychology, 1971, 90. 227-234.

MCClelland, J. L. Preliminary letter identification in the perception of words and nonwords. Journal of Experimental Psychology: Human Perception and Performance. 1976, 2, 80-91.

Pollatsek, A.. Well. A. D., \& Schindler, R. $M$. Familiarity affects visual processing of words. Journal of Experimentai Psychology: Human Perception and Pertormance, 1975, 1, 328-338.

Roscr. E. Cognitive representations of semantic categories. Journal of Experimental Psychology: General. 1975, 104, 192-233.

Schaeffer, B., \& Wallace, R. The comparison of word meanings. Journal of Experimental Psycnology, 1970, 86. $144-152$.

Smith, E. E., Shoben, E. J., \& Rips. L. J. Structure and process in semantic memory: A featural model for semantic decisions. Psychological Review, 1974, 81, 214-241.
Solso, R. L., \& King, J. F. Frequency and versatility of letters in the English language. Behavior Research Methods \& Instrumentation, 1976, 8, 283-286.

\section{NOTE}

1. Similar difficulties of interpretation appear to exist in a recent experiment by Pollatsek, Well, and Schindler (1975). They found that different judgments for pairs of homophones (e.g., SITE/CITE), which differed by only one letter, produced a word/orthographically illegal nonword (e.g., BSHA/DSHA) difference which was of the same magnitude as that obtained for different judgments of two identical words which differed only in letter case (e.g., cITE/CITE vs dSHA/DSHA). Similar results have been obtained by Besner and Jackson (1975). Pollatsek et al. (1975) argued that their results rule out a semantic or lexical (they did not make the distinction) interpretation of the word/orthographically illegal nonword difference, at least at the comparison level, because their familiarity effect was of the same magnitude regardless of whether the subject responded to semantically identical or nonidentical words. It is possible, however, that their casedifferent word pairs were encoded more rapidly, but compared more slowly than their letter-different word pairs. This differential tradeoff between the speed of encoding and comparison of the two types of word pairs could have produced their findings.

(Received for publication May 3, 1977; revision accepted May 13,1977.)

Appendix A

The word pairs used in Experiments $1 \mathrm{a}$ and $\mathrm{lb}$ are listed below together with the mean reaction time in milliseconds for each pair and the mean semantic relatedness score $(R)$ for the semantically related and unrelated pairs.

\begin{tabular}{|c|c|c|c|c|c|}
\hline & \multicolumn{3}{|c|}{ "Same" Judgments } & \multirow[b]{2}{*}{$1 \mathrm{a}$} & \multirow[b]{2}{*}{$1 \mathrm{~b}$} \\
\hline & $1 \mathrm{a}$ & $1 \mathrm{~b}$ & & & \\
\hline bleed/bleed & 945 & 586 & disgust/disgust & 868 & 611 \\
\hline rank/rank & 960 & 694 & sleep/sleep & 788 & 558 \\
\hline $\mathrm{dish} / \mathrm{dish}$ & 814 & 588 & fiend/fiend & 929 & 702 \\
\hline algebra/algebra & 924 & 718 & peel/peel & 778 & 604 \\
\hline defeat/defeat & 890 & 659 & quartet/quartet & 979 & 701 \\
\hline skirt/skirt & 857 & 619 & antigen/antigen & 1023 & 650 \\
\hline charge/charge & 861 & 615 & pole/pole & 898 & 763 \\
\hline unify/unify & 812 & 608 & confine/confine & 871 & 637 \\
\hline icy/icy & 760 & 587 & chores/chores & 894 & 636 \\
\hline adverb/adverb & 893 & 616 & duct/duct & 856 & 579 \\
\hline advice/advice & 892 & 630 & electron/electron & 852 & 682 \\
\hline confide/confide & 984 & 627 & untie/untie & 943 & 729 \\
\hline poet/poet & 843 & 604 & discard/discard & 874 & 616 \\
\hline frock/frock & 864 & 655 & arabia/arabia & 922 & 676 \\
\hline duel/duel & 886 & 652 & sang/sang & 990 & 603 \\
\hline shine/shine & 862 & 592 & algiers/algiers & 1037 & 695 \\
\hline blast/blast & 882 & 602 & define/define & 823 & 654 \\
\hline grunt/grunt & 902 & 613 & quarrel/quarre1 & 910 & 684 \\
\hline ancient/ancient & 877 & 638 & groom/groom & 913 & 600 \\
\hline bland/bland & 983 & 643 & antique/antique & 852 & 637 \\
\hline shell/shell & 827 & 580 & sleep/sleep & 843 & 607 \\
\hline blame/blame & 1071 & 630 & archive/archive & 1033 & 742 \\
\hline election/election & 930 & 673 & choral/choral & 951 & 634 \\
\hline smirk/smirk & 900 & 595 & dart/dart & 839 & 586 \\
\hline arctic/arctic & 891 & 723 & archery/archery & 959 & 642 \\
\hline gleam/gleam & 861 & 591 & beer/beer & 880 & 552 \\
\hline soon/soon & 828 & 616 & peep/peep & 843 & 590 \\
\hline choice/choice & 880 & 625 & smelt/smelt & 1082 & 641 \\
\hline inn/inn & 826 & 610 & bred/bred & 1030 & 631 \\
\hline rung/rung & 962 & 626 & glide/glide & 929 & 652 \\
\hline
\end{tabular}




\begin{tabular}{|c|c|c|c|c|c|c|c|}
\hline \multicolumn{8}{|c|}{ Semantically Related (SR) "Different" Judgments } \\
\hline & $1 \mathrm{a}$ & $1 b$ & $\mathbf{R}$ & & $1 \mathbf{a}$ & $1 \mathrm{~b}$ & $\mathbf{R}$ \\
\hline $\begin{array}{l}\text { electric/electron } \\
\text { disgust/disdain } \\
\text { dart/dash } \\
\text { gleam/glint } \\
\text { quartet/quarter } \\
\text { archaic/archive } \\
\text { ancient/archive } \\
\text { bleed/blood } \\
\text { smile/smirk } \\
\text { ice/icy } \\
\text { sang/song } \\
\text { choice/choose } \\
\text { choral/chorus } \\
\text { duel/duet } \\
\text { peep/peer }\end{array}$ & $\begin{array}{r}876 \\
866 \\
907 \\
846 \\
999 \\
877 \\
904 \\
862 \\
869 \\
909 \\
920 \\
934 \\
906 \\
996 \\
1003\end{array}$ & $\begin{array}{l}633 \\
686 \\
659 \\
623 \\
717 \\
679 \\
643 \\
611 \\
655 \\
673 \\
643 \\
647 \\
616 \\
701 \\
662 \\
\end{array}$ & $\begin{array}{l}2.41 \\
3.88 \\
3.75 \\
4.06 \\
2.00 \\
3.90 \\
4.09 \\
4.50 \\
4.09 \\
4.56 \\
4.53 \\
4.38 \\
4.03 \\
1.41 \\
1.47\end{array}$ & $\begin{array}{l}\text { arabia/arabic } \\
\text { confide/confess } \\
\text { sleep/sheet } \\
\text { ancient/antique } \\
\text { blast/blaze } \\
\text { rang/rung } \\
\text { poem/poet } \\
\text { grunt/groan } \\
\text { defeat/defend } \\
\text { algiers/algeria } \\
\text { advise/advice } \\
\text { fiend/freak } \\
\text { brew/beer } \\
\text { shirt/skirt } \\
\text { unify/unite }\end{array}$ & $\begin{array}{r}979 \\
879 \\
872 \\
916 \\
863 \\
971 \\
917 \\
882 \\
885 \\
927 \\
1047 \\
915 \\
908 \\
1045 \\
1005 \\
\end{array}$ & $\begin{array}{l}673 \\
659 \\
665 \\
624 \\
640 \\
652 \\
646 \\
614 \\
630 \\
716 \\
730 \\
671 \\
626 \\
781 \\
643 \\
\end{array}$ & $\begin{array}{l}4.66 \\
3.77 \\
2.00 \\
4.44 \\
1.78 \\
4.63 \\
4.38 \\
4.06 \\
1.63 \\
4.09 \\
4.59 \\
1.69 \\
4.31 \\
3.19 \\
4.06 \\
\end{array}$ \\
\hline \multicolumn{8}{|c|}{ Semantically Unrelated (SU) “Different" Judgments } \\
\hline & 1a & $1 b$ & $\mathbf{R}$ & & $1 \mathrm{a}$ & $1 \mathrm{~b}$ & $\mathbf{R}$ \\
\hline $\begin{array}{l}\text { glide/glint } \\
\text { poem/pole } \\
\text { shine/shirt } \\
\text { defend/define } \\
\text { ice/inn } \\
\text { freak/frock } \\
\text { blood/bland } \\
\text { unite/untie } \\
\text { quarrel/quartet } \\
\text { duet/duct } \\
\text { sang/soon } \\
\text { smile/smelt } \\
\text { archaic/archery } \\
\text { ancient/archery } \\
\text { chores/chorus }\end{array}$ & $\begin{array}{r}857 \\
838 \\
882 \\
876 \\
874 \\
875 \\
874 \\
1146 \\
975 \\
929 \\
983 \\
960 \\
941 \\
942 \\
1041\end{array}$ & $\begin{array}{l}616 \\
596 \\
657 \\
707 \\
612 \\
592 \\
601 \\
880 \\
656 \\
655 \\
642 \\
616 \\
636 \\
598 \\
692\end{array}$ & $\begin{array}{l}1.75 \\
1.00 \\
1.00 \\
1.06 \\
1.03 \\
1.00 \\
1.03 \\
1.09 \\
1.00 \\
1.00 \\
1.00 \\
1.00 \\
1.06 \\
1.03 \\
1.03\end{array}$ & $\begin{array}{l}\text { electric/election } \\
\text { algebra/algeria } \\
\text { brew/bred } \\
\text { arabic/arctic } \\
\text { sheet/shell } \\
\text { ancient/antigen } \\
\text { charge/choose } \\
\text { blame/blaze } \\
\text { advise/adverb } \\
\text { rang/rank } \\
\text { groan/groom } \\
\text { disdain/discard } \\
\text { confine/confess } \\
\text { dish/dash } \\
\text { peer/peel }\end{array}$ & $\begin{array}{r}896 \\
1025 \\
992 \\
980 \\
919 \\
912 \\
910 \\
1014 \\
896 \\
1021 \\
930 \\
845 \\
851 \\
920 \\
893\end{array}$ & $\begin{array}{l}669 \\
782 \\
642 \\
655 \\
637 \\
677 \\
631 \\
638 \\
658 \\
644 \\
626 \\
642 \\
650 \\
622 \\
639\end{array}$ & $\begin{array}{l}1.00 \\
1.00 \\
1.25 \\
1.13 \\
1.16 \\
1.13 \\
1.06 \\
1.00 \\
1.00 \\
1.00 \\
1.00 \\
1.22 \\
1.09 \\
1.06 \\
1.00\end{array}$ \\
\hline
\end{tabular}

\section{Appendix B}

The word pairs used in Experiment 2 are listed below together with the mean reaction time (RT) in milliseconds for each pair and the mean semantic relatedness score $(R)$ for the semantically related and unrelated pairs.

\begin{tabular}{|c|c|c|c|}
\hline & $\begin{array}{l}\text { Identi } \\
\text { RT }\end{array}$ & ddgments & RT \\
\hline $\begin{array}{l}\text { position/position } \\
\text { tool/tool } \\
\text { dune/dune } \\
\text { attack/attack } \\
\text { donkey/donkey } \\
\text { player/player } \\
\text { laugh/laugh } \\
\text { mine/mine } \\
\text { billion/billion } \\
\text { tomorrow/tomorrow } \\
\text { alive/alive } \\
\text { strike/strike } \\
\text { vice/vice } \\
\text { define/define } \\
\text { cow/cow } \\
\text { pistol/pistol } \\
\text { access/access } \\
\text { pupil/pupil } \\
\text { fault/fault } \\
\text { phony/phony }\end{array}$ & $\begin{array}{l}492 \\
515 \\
499 \\
507 \\
527 \\
530 \\
504 \\
521 \\
514 \\
508 \\
514 \\
559 \\
502 \\
500 \\
496 \\
517 \\
537 \\
520 \\
499 \\
491\end{array}$ & $\begin{array}{l}\text { purple/purple } \\
\text { grin/grin } \\
\text { snap/snap } \\
\text { dump/dump } \\
\text { bug/bug } \\
\text { bait/bait } \\
\text { adore/adore } \\
\text { armory/armory } \\
\text { arbor/arbor } \\
\text { discord/discord } \\
\text { concise/concise } \\
\text { belt/belt } \\
\text { furnish/furnish } \\
\text { wrap/wrap } \\
\text { lark/lark } \\
\text { carbon/carbon } \\
\text { stem/stem } \\
\text { radical/radical } \\
\text { blanket/blanket } \\
\text { crucial/crucial }\end{array}$ & $\begin{array}{l}486 \\
552 \\
515 \\
519 \\
537 \\
498 \\
516 \\
533 \\
513 \\
518 \\
513 \\
505 \\
491 \\
529 \\
529 \\
554 \\
518 \\
543 \\
518 \\
492\end{array}$ \\
\hline
\end{tabular}




\begin{tabular}{|c|c|c|c|c|c|}
\hline \multicolumn{6}{|c|}{ Semantically Related (SR) "Same" Judgments } \\
\hline & RT & $\mathbf{R}$ & & RT & $\mathbf{R}$ \\
\hline advise/advice & 500 & 4.59 & choral/chorus & 566 & 4.03 \\
\hline algiers/algeria & 539 & 4.09 & confide/confess & 571 & 3.77 \\
\hline ancient/archive & 545 & 4.09 & defeat/defend & 554 & 1.63 \\
\hline ancient/antique & 493 & 4.44 & duel/duet & 554 & 1.41 \\
\hline arabia/arabic & 502 & 4.66 & electron/electric & 540 & 2.41 \\
\hline fiend/freak & 606 & 1.69 & disgust/disdain & 545 & 3.88 \\
\hline bleed/blood & 494 & 4.50 & grunt/groan & 606 & 4.06 \\
\hline blast/blaze & 580 & 1.78 & ice/icy & 591 & 4.56 \\
\hline brew/beer & 541 & 4.31 & dart/dash & 594 & 3.75 \\
\hline choice/choose & 532 & 4.38 & peep/peer & 533 & 1.47 \\
\hline gleam/glint & 620 & 4.06 & intend/intent & 531 & 3.94 \\
\hline poem/poet & 563 & 4.38 & major/minor & 556 & 2.28 \\
\hline quartet/quarter & 539 & 2.00 & tones/tonal & 550 & 4.31 \\
\hline rang/rung & 576 & 4.63 & adversity/adversary & 538 & 1.40 \\
\hline sang/song & 528 & 4.53 & foot/feet & 559 & 4.56 \\
\hline skirt/shirt & 570 & 3.19 & bland/blank & 508 & 1.41 \\
\hline sleep/sheet & 555 & 2.00 & pelvic/pelvis & 505 & 2.40 \\
\hline smile/smirk & 550 & 4.09 & flora/fauna & 622 & 3.13 \\
\hline unify/unite & 578 & 4.06 & worse/worst & 578 & 4.53 \\
\hline archaic/archive & 514 & 3.90 & frost/froze & 567 & 4.41 \\
\hline \multicolumn{6}{|c|}{ Semantically Unrelated (SU) "Same" Judgments } \\
\hline & RT & $\mathbf{R}$ & & $\mathrm{RT}$ & $\mathbf{R}$ \\
\hline advise/adverb & 514 & 1.00 & chores/chorus & 534 & 1.03 \\
\hline algebra/algeria & 516 & 1.00 & confine/confess & 511 & 1.09 \\
\hline ancient/archery & 533 & 1.03 & defend/define & 546 & 1.06 \\
\hline ancient/antigen & 563 & 1.13 & $\mathrm{duet} / \mathrm{duct}$ & 540 & 1.00 \\
\hline arabic/arctic & 563 & 1.13 & electric/election & 504 & 1.00 \\
\hline freak/frock & 591 & 1.00 & disdain/discard & 543 & 1.22 \\
\hline blood/bland & 536 & 1.03 & groan/groom & 553 & 1.00 \\
\hline blame/blaze & 536 & 1.00 & ice/inn & 702 & 1.03 \\
\hline brew/bred & 567 & 1.25 & dish/dash & 542 & 1.06 \\
\hline charge/choose & 583 & 1.06 & peer/peel & 604 & 1.00 \\
\hline glide/glint & 539 & 1.75 & intend/intake & 544 & 1.06 \\
\hline poem/pole & 536 & 1.00 & major/magic & 597 & 1.00 \\
\hline quarrel/quarter & 561 & 1.00 & tones/tooth & 533 & 1.00 \\
\hline rang/rank & 688 & 1.00 & advertise/adversary & 581 & 1.16 \\
\hline sang/soon & 522 & 1.00 & feed/feet & 542 & 1.00 \\
\hline shine/shirt & 539 & 1.00 & block/blank & 589 & 1.16 \\
\hline sheet/shell & 568 & 1.16 & pelvic/pencil & 529 & 1.00 \\
\hline smile/smelt & 530 & 1.00 & flora/flake & 504 & 1.06 \\
\hline unite/untie & 550 & 1.09 & worst/worth & 546 & 1.00 \\
\hline archaic/archery & 584 & 1.06 & frown/frost & 565 & 1.00 \\
\hline
\end{tabular}

High Shared-Letter (HSL) "Different" Judgments

\begin{tabular}{|c|c|c|c|}
\hline & RT & & RT \\
\hline hook/lack & 638 & snake/flake & 582 \\
\hline poke/cake & 619 & suspect/protect & 596 \\
\hline hide/fade & 614 & insect/direct & 595 \\
\hline block/stack & 606 & mental/dental & 641 \\
\hline soap/camp & 595 & depth/teeth & 616 \\
\hline map/tap & 652 & lunch/touch & 613 \\
\hline hate/kite & 651 & plot/slot & 628 \\
\hline psychology/immunology & 618 & sinner/winter & 597 \\
\hline plant/grant & 632 & whirl/pearl & 567 \\
\hline rush/push & 644 & turtle/purple & 582 \\
\hline meat/heat & 658 & tumble/rumble & 681 \\
\hline carrot/parrot & 614 & trash/flash & 716 \\
\hline cedar/radar & 614 & trust/crust & 569 \\
\hline cavern/tavern & 572 & mould/could & 603 \\
\hline fascinate/negotiate & 544 & fair/pair & 644 \\
\hline drown/frown & 568 & dollar/pillar & 689 \\
\hline bright/flight & 624 & cough/touch & 597 \\
\hline joke/sake & 578 & dream/steam & 586 \\
\hline stapples/nipples & 638 & drink/trick & 600 \\
\hline yoke/fake & 605 & reflect/neglect & 652 \\
\hline
\end{tabular}




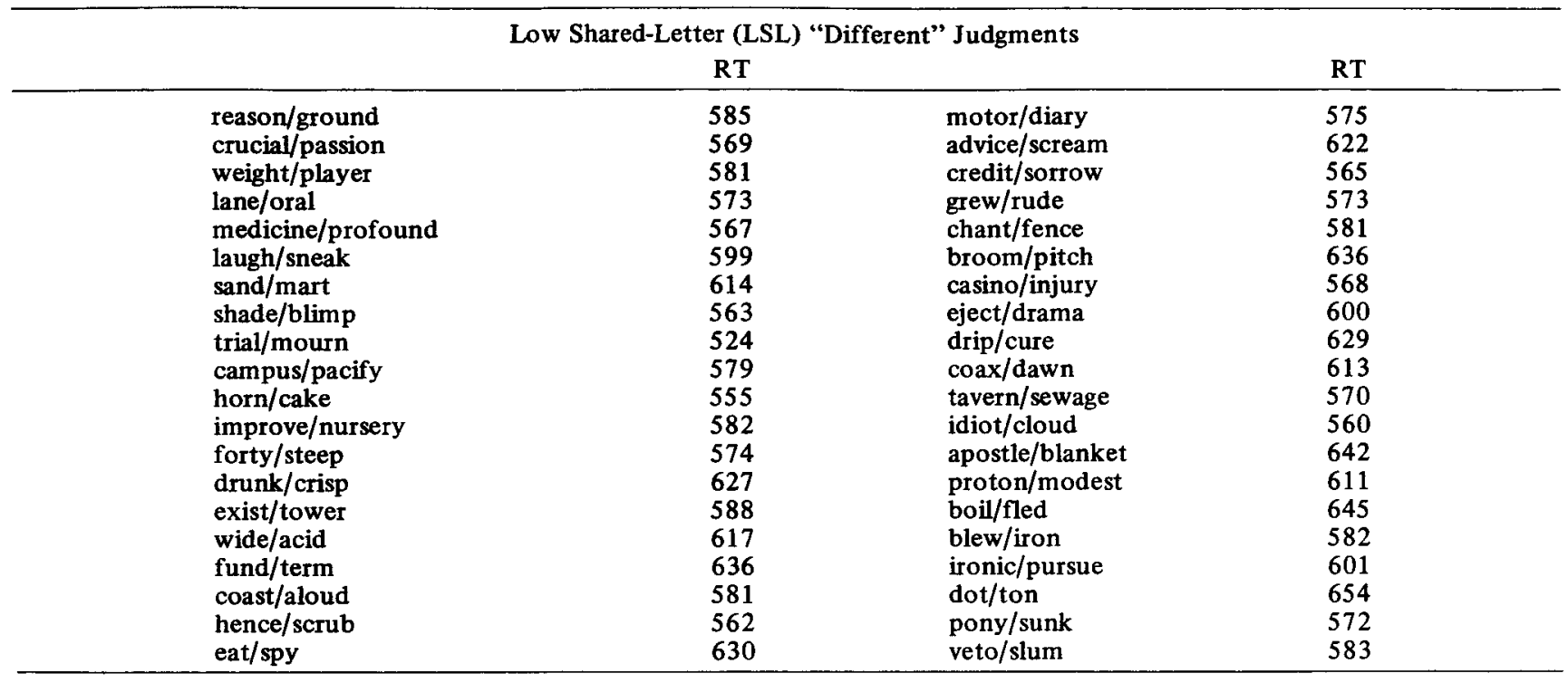

Appendix C

The item pairs used in Experiment 3 are listed below together with the mean reaction time for each pair.

\begin{tabular}{|c|c|c|c|c|c|c|c|}
\hline \multicolumn{4}{|c|}{ Words ("Same" Judgments) } & \multicolumn{4}{|c|}{ Nonwords ("Same" Judgments) } \\
\hline \multicolumn{2}{|r|}{ RT } & & RT & \multicolumn{2}{|c|}{ RT } & & \multirow{2}{*}{$\frac{\text { RT }}{924}$} \\
\hline wheat/wheat & 1032 & queen/queen & 980 & blout/blout & 902 & chand/chand & \\
\hline guard/guard & 745 & paint/paint & 859 & sonth/sonth & 997 & blong/blong & 824 \\
\hline smoke/smoke & 918 & score/score & 843 & graim/graim & 822 & chall/chall & 807 \\
\hline learn/learn & 805 & price/price & 760 & pight/pight & 881 & stire/stire & 834 \\
\hline fruit/fruit & 851 & scale/scale & 887 & selch/selch & 883 & banch/banch & 779 \\
\hline catch/catch & 771 & noise/noise & 928 & minch $/$ minch & 1010 & whoce/whoce & 843 \\
\hline brush/brush & 849 & cloth/cloth & 822 & fleep/fleep & 827 & brult/brult & 813 \\
\hline drink/drink & 842 & pride/pride & 794 & starp/starp & 879 & chist/chist & 853 \\
\hline fight/fight & 765 & state/state & 849 & thest/thest & 807 & litch/litch & 837 \\
\hline sleep/sleep & 796 & sound/sound & 821 & rilse/rilse & 863 & pring/pring & 770 \\
\hline short/short & 966 & found/found & 725 & hilch/hilch & 961 & dring/dring & 921 \\
\hline spend/spend & 809 & would/would & 895 & thove/thove & 947 & therp/therp & 893 \\
\hline stage/stage & 873 & death/death & 820 & drash/drash & 925 & sterk/sterk & 928 \\
\hline knife/knife & 941 & worth/worth & 766 & slart/slart & 989 & sping/sping & 836 \\
\hline build/build & 876 & threw/threw & 771 & frind/frind & 838 & shint/shint & 852 \\
\hline faith/faith & 816 & three/three & 798 & smace/smace & 1073 & woult/woult & 884 \\
\hline guess/guess & 868 & space/space & 796 & blace/blace & 844 & glast/glast & 881 \\
\hline porch/porch & 776 & plant/plant & 830 & bling/bling & 806 & preat/preat & 909 \\
\hline stand/stand & 882 & train/train & 819 & theam/theam & 910 & broul/broul & 918 \\
\hline white/white & 747 & voice/voice & 896 & shisk/shisk & 858 & chesk/chesk & 825 \\
\hline \multicolumn{4}{|c|}{ Words ("Different” Judgments) } & \multirow{2}{*}{\multicolumn{3}{|c|}{ Nonwords ("Different" Judgments) }} & \\
\hline & $\mathbf{R T}$ & & RT & & & & RT \\
\hline blood/world & 827 & cheer/flesh & 815 & brone/chout & 815 & thear/whosk & 895 \\
\hline grain/north & 900 & sleep/broad & 888 & geark/carth & 954 & wherp/clest & 984 \\
\hline beach/thick & 855 & share/house & 887 & bruld/theng & 941 & thire/shong & 854 \\
\hline dress/might & 914 & shook/month & 925 & drout/nould & 868 & dreak/wonth & 856 \\
\hline class/earth & 962 & green/block & 850 & cound/trong & 875 & brean/flost & 845 \\
\hline mount/bring & 929 & store/thank & 847 & moulk/breet & 893 & coure/thace & 901 \\
\hline youth/grass & 832 & crowd/smell & 795 & yould/thare & 937 & thead/sterm & 939 \\
\hline brave/touch & 914 & chain/shell & 855 & brich/shice & 920 & shain/cherd & 906 \\
\hline blame/chief & 807 & clean/track & 809 & briss/shend & 862 & smain/trand & 801 \\
\hline bound/grant & 812 & grand/stock & 883 & boult/cloor & 938 & plard/wouch & 819 \\
\hline horse/brown & 1016 & child/round & 844 & worch/plart & 873 & moung/roult & 829 \\
\hline trick/clear & 893 & dream/flame & 854 & trind/smair & 935 & couse/friss & 805 \\
\hline
\end{tabular}




\begin{tabular}{|c|c|c|c|c|c|c|c|}
\hline \multirow{2}{*}{\multicolumn{3}{|c|}{$\begin{array}{l}\text { Words ("Different" Judgments) } \\
\text { RT }\end{array}$}} & \multicolumn{5}{|c|}{ Nonwords ("Different" Judgments) } \\
\hline & & & RT & & RT & & RT \\
\hline $\begin{array}{l}\text { shall/chair } \\
\text { small/crown } \\
\text { think/storm } \\
\text { black/greet } \\
\text { mouth/shoot } \\
\text { stick/cheek } \\
\text { bread/sharp } \\
\text { flash/sweet }\end{array}$ & $\begin{array}{r}1019 \\
813 \\
908 \\
836 \\
875 \\
928 \\
836 \\
795\end{array}$ & $\begin{array}{l}\text { march/grave } \\
\text { speak/count } \\
\text { judge/south } \\
\text { smile/glass } \\
\text { field/press } \\
\text { stone/teach } \\
\text { heart/brain } \\
\text { teeth/flood }\end{array}$ & $\begin{array}{r}837 \\
896 \\
894 \\
857 \\
880 \\
873 \\
1034 \\
936\end{array}$ & $\begin{array}{l}\text { chard/shair } \\
\text { starm/thean } \\
\text { thice/courm } \\
\text { flast/breat } \\
\text { wouth/dreat } \\
\text { shing/thirp } \\
\text { whesk/theak } \\
\text { clast/whert }\end{array}$ & $\begin{array}{r}904 \\
1002 \\
891 \\
919 \\
875 \\
868 \\
940 \\
852\end{array}$ & $\begin{array}{l}\text { mousk/sould } \\
\text { shace/grich } \\
\text { bleam/coulk } \\
\text { stirm/gound } \\
\text { shent/prout } \\
\text { cousk/truld } \\
\text { gruld/beark } \\
\text { jance/frone }\end{array}$ & $\begin{array}{r}1012 \\
1006 \\
847 \\
902 \\
924 \\
850 \\
827 \\
884\end{array}$ \\
\hline
\end{tabular}

